\title{
Analysis of professional quality of students majored with logistics management in the higher vocational college based on AHP
}

\author{
Chengxia Dai \& Long Su \\ Changjiang Polytechnic, Wuhan, Hubei, China \\ Hubei Skilled Talent Cultivation Research Center, Wuhan, Hubei, China \\ Feng He \\ Huazhong University of Science and Technology, Wuhan, Hubei, China
}

\begin{abstract}
To strength training of the professional quality of students in the higher vocational college, and then explore an effective way to train the professional quality of students in the higher vocational college is a very necessary and urgent task. On this basis, this paper aims at investigating the situation of the professional quality of the students majored with the logistics management in the higher vocational college according to the requirements of the industry and enterprise, constructs a multi-dimensional space of the professional quality by the use of the AHP analysis method, and proposes the training method of the professional quality, in order to further improve the professional quality of students in the higher vocational college, and provide reference for the training of the students majored with the logistics management in the higher vocational college.
\end{abstract}

Keywords: higher vocational college; professional quality; logistics management

China's higher vocational education has developed for thirty years, and also made remarkable achievements. The higher vocational education has occupied half of higher education. In 2014, Decision of the State Council on Accelerating the Development of Modern Vocational Education (G. F. [2014] No. 19) proposed that the higher vocational colleges should fully implement quality education, scientifically and rationally set up curriculums, and penetrate the professional ethics and humanistic quality education in the entire process of training. In 2015, Several Opinions of the Ministry of Education on Deepening Vocational Education and Teaching Reform to Fully Improve Quality of Personnel Training (J. Z. C. [2015] No. 6) further clarified that, to highly integrate the improvement of the students' professional skills with training of the professional spirit, to actively explore effective ways and means to form a normalized and long-acting mechanism of training professional spirit, develop good professional ethics, and enhance the students' awareness and understanding of the professional idea, professional responsibility and professional mission.

According to the data statistics of 2015 China Graduate Employment Report of MyCOS, the em- ployment rate of the graduates in the higher vocational colleges in 2014 is $91.5 \%$ after six months, which is slightly higher than that in 2013 (90.9\%); the logistics management specialty is included in 50 major higher vocational specialties with the highest average monthly income in 2013. China Education Online summarizes that, the logistics management specialty is one of ten higher vocational specialties with good development prospects. The post promotion ratio of the graduates majored with the logistics management is $70 \%$ within three years. Thus, the logistics management specialty has a very good employment prospect.

However, the separation rate of the students in the higher vocational colleges is relatively high. According to the statistics of 2014 China Graduate Employment Report of MyCOS, the separation rate of the students in the higher vocational colleges in 2014 is $42 \%$ within six months. According to the statistics of Puxin Research Institute, in 2013, the logistics is one of three industries with the highest separation rate, with the separation rate of $30.2 \%$; on the other hand, for the enterprises, companies and other social employers, the graduates in the higher vocational colleges fail to 
reach their work requirements in practical skills and abilities in the short term, and the requirements of the students' professional quality are also incompatible with the enterprise requirements. In terms of the feedback of the employers, some employed students are not practical in the post, and lack of teamwork and hard-working spirit, and also have problems in the following respects, grandiose aims but puny abilities, poor psychological quality, poor adaptive capacity, or wide ambition beyond their grasp, greater mobility and so on. The social employers have a lower comprehensive evaluation on the students in the higher vocational colleges, and hope that the higher vocational colleges can make efforts to increase training of the students' professional quality.

\section{CONNOTATION OF PROFESSIONAL QUALITY}

Professional quality refers to an internal and relatively stable basic quality of the practitioners formed and developed by education and training, professional practice, self-cultivation and other ways based on a certain physiological and psychological condition, which plays a decisive role in professional activities. In general, the professional quality contains the main content of the following three aspects: professional knowledge and ability, professional ethics and professional spirit. The professional knowledge and ability is the primary factor to constitute the professional quality, which is the knowledge and technical capacity possessed by a person who is engaged in a certain job; the professional ethics is the professional norm to measure a person's work attitude, which is the basis of the professional quality, covering dedication, legal compliance, hospitality and other content; the professional spirit is the soul of the professional quality. The theoretical connotation of the professional spirit contains the professional ideal, professional attitude, professional responsibility, professional reputation, professional style and other basic content ${ }^{[1]}$.

The composition of the professional quality mainly has the following two models: quality iceberg model and professional quality triangle model.

\subsection{Quality iceberg model}

Lyle. M. Spencer, an American scholar divides the quality into following five aspects, that is, knowledge and skills, social role, self-image, personality and motivation, and proposes the concept of the quality iceberg model (see Figure 1), and considers that the quality of an employee is like an iceberg. "Above-water portion" of the employee's quality is the qualification, knowledge, behavior and skills, and presents in the horizon of people, accounting for $1 / \mathrm{m}^{2}$ which is dominant. "Under-water portion" of the $\mathrm{e}$ ployee's quality is below the water surface, which is recessive, and forms a cornerstone by the professional ideal, professional ethics and professional attitude and so on ${ }^{[2]}$. For employees, it is relatively easy to change and develop 1/8 above the iceberg, and also relatively easy to achieve achievement after training, but it very difficult to fundamentally solve the problems of the comprehensive quality of the employees. $7 / 8 \mathrm{~b}$ low the iceberg is often overlooked by people. If the recessive quality of the employees can get enough training, it will have a great impact on the promotion of the employees and also have a far-reaching impact on the enterprise.

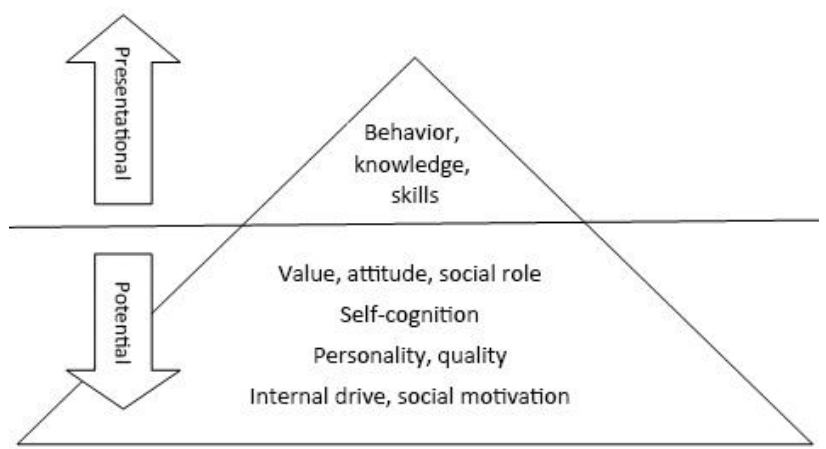

Figure 1. Quality iceberg model

\subsection{Triangular model of professional quality}

Professional quality triangle model (Figure 2) consi ${ }^{\mathrm{d}}$ ers that the professional quality is comprised by three elements: supporting element, safeguarding element and expansion element. The supporting element is the

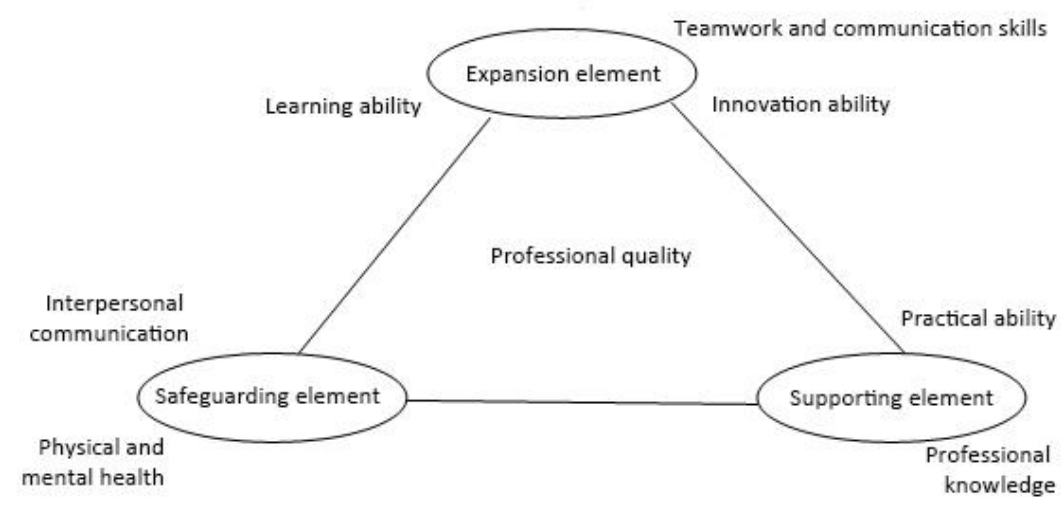

Figure 2. Triangular model of professional quality 


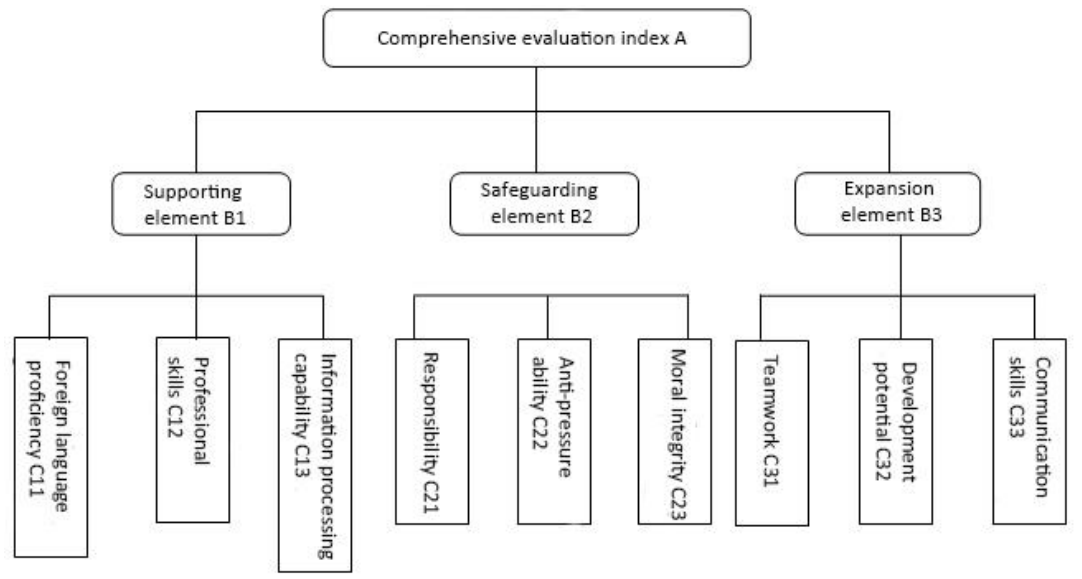

Figure 3. Evaluation system

professional knowledge and practical ability essential to be competent in a certain post (group), which plays a fundamental supporting role in a certain post. The safeguarding element refers to the element requisite for the practitioners, and plays a fundamental safeguarding role in a certain post (group), which mainly contains three sub-elements, that is, physical and mental health, ideology and morality, and interpersonal communication. The expansion element concerns the sustainable development of the practitioners, which mainly contains the learning ability, innovation ability, teamwork, communication skills and so on. Three elements of the professional quality have an interaction effect, which form a complete system.

The author carries out the questionnaire survey for the following seventeen logistics units, such as Dangdang Information Technology Co., Ltd., Hubei SF Express, Changjiu Logistics Guangzhou Branch, Hubei Yuxin Logistics, ANJI CEVA, Yingsu Logistics, Yuancheng Logistics, Shanghai Kejie Logistics, Jiangsu Jingdong Information Technology Co., Ltd., and so on, and investigation of the professional quality of the students majored with the logistics management in the higher vocational colleges. According to the investigation results, the employers no longer measure the students in the higher vocational colleges simply relying on the education background and scores, but they pay more attention to whether the graduates have the professional quality, such as the team spirit, responsibility, hard work, ethical performance, professional skills and communication skills and so on. On this basis, the professional quality model of AHP is constructed based on the professional quality triangle model.

\section{CONSTRUCTION OF PROFESSIONAL QUALITY MODEL OF AHP}

Analytic Hierarchy Process (AHP for short) is a kind of hierarchical weight decision analysis method, proposed by Saaty, an American operations researcher and professor of Pittsburgh University in the early 1970s. It refers to a system method that a complex multi-objective decision problem is decomposed into multiple targets or codes as a system, and then broken down into several levels of multiple indicators (or codes, constraints), and then the single hierarchical ranking (weight number) and overall ranking is calculated by the fuzzy quantization method of the qualitative indicator as a target (multiple indicators) and multi-scheme optimized decision. AHP can be used to construct the judgment matrix, thus solving the maximum eigenvalue, and the corresponding eigenvector $\mathrm{W}$, that is, the weight of relative importance of the indicator in a certain level for the relevant indicator in an upper level after normalization.

\subsection{Construction of a hierarchical structure model}

According to the hierarchical structure of AHP, AHP evaluation system can be established through visits, telephone interviews and questionnaire surveys of 17 logistics units, as shown in Figure 3. The evaluation index system sets up three Level-I indicators and several Level-II indicators from the following three aspects: safeguarding element, supporting element and expansion element on the basis of the triangular model of professional quality, with the judgment indicator set up by the questionnaire content.

\subsection{Scale setting}

The establishment of the evaluation scale and level is shown in Table 1

Table 1. Evaluation scale

\begin{tabular}{|l|l|}
\hline Evaluation description & Score \\
\hline Extremely important & 9 \\
\hline Very important & 7 \\
\hline Obviously important & 5 \\
\hline Slightly important & 3 \\
\hline Equally important & 1 \\
\hline $\begin{array}{l}\text { The intermediate values, 2, 4, } 6 \text { and } 8 \text { are between various } \\
\text { scores. If there is a core for the project } \mathrm{i} \text { to the project } \mathrm{j}, \text { then } \\
\text { the score of the project } \mathrm{j} \text { to the project } \mathrm{i} \text { is its reciprocal. }\end{array}$ \\
\hline
\end{tabular}




\subsection{Construction of judgment matrix}

The judgment matrix of the different factors of the professional quality can be constructed according to the hierarchical structure model constructed above (Figure 3). Based on the statistical results of the questionnaire survey and comprehensive analysis of the author's understanding, as well as the assignment criterion in Table 1, there is a need to make pairwise comparison of two factors and construct the judgment matrix of A (Table 2), B1 (Table 3), B2 (Table 4 ) and B3 (table 5).

Table 2. A

\begin{tabular}{l|l|l|l}
\hline & B1 & B2 & B3 \\
\hline B1 & 1 & 2 & 3 \\
B2 & 0.5 & 1 & 2 \\
B3 & 0.33 & 0.5 & 1 \\
\hline
\end{tabular}

Table 3. B1

\begin{tabular}{l|l|l|l}
\hline & C11 & C12 & C13 \\
\hline C11 & 1 & 0.5 & 0.5 \\
C12 & 2 & 1 & 2 \\
C13 & 2 & 0.5 & 1 \\
\hline
\end{tabular}

Table 4. B2

\begin{tabular}{l|l|l|l}
\hline & C21 & C22 & C23 \\
\hline C21 & 1 & 3 & 0.25 \\
C22 & 0.33 & 1 & 0.2 \\
C23 & 4 & 5 & 1 \\
\hline
\end{tabular}

Table 5. B3

\begin{tabular}{l|l|l|l}
\hline & C31 & C32 & C33 \\
\hline C31 & 1 & 2 & 0.33 \\
C32 & 0.5 & 1 & 0.5 \\
C33 & 3 & 2 & 1 \\
\hline
\end{tabular}

\subsection{Calculation of eigenvectors and eigenvalues of each matrix, and consistency test}

The matlab software can be used to calculate $\mathrm{W}=$ $(0.5400,0.2971,0.1629), \lambda \max =3.01$, and carry out consistency test:

$$
C . I=\frac{\lambda \max -\mathrm{n}}{\mathrm{n}-1}=\frac{3.01-3}{3-1}=0.005
$$

Through querying the random consistency pointer table of the same order evaluation, $\mathrm{RI}=0.58$;

$$
C . R=\frac{C . I}{R . I}=0.009 \prec 0.1
$$

Meet the requirements of consistency.

Similarly, B1, B2 and B3 can be calculated.

$\mathrm{W} 1=(0.1958,0.4934,0.3108) \mathrm{T}, \lambda \max =3.05$, C. $R=0.025<0.1$;

$\mathrm{W} 2=(0.2255,0.1004,0.6741) \mathrm{T}, \lambda \max =3.08$, C.R $=0.04<0.1$;
$\mathrm{W} 3=(0.5474,0.2627,0.1899) \mathrm{T}, \lambda \max =3.13$, $\mathrm{C} . \mathrm{R}=0.065<0.1$. Meet the requirements of consistency.

\subsection{Calculation of total level of sorting}

The results of the total level of sorting are shown in Table 6:

Table 6

\begin{tabular}{|l|l|l|l|l|l|l|l|l|}
\hline C11 & C12 & C13 & C21 & C22 & C23 & C31 & C32 & C33 \\
\hline 0.11 & 0.26 & 0.17 & 0.07 & 0.03 & 0.20 & 0.09 & 0.04 & 0.03 \\
\hline
\end{tabular}

Viewing from the criterion layer $\mathrm{B}$, the weight of each factor is W1>W2>W3, indicating the degree of importance of the supporting element, safeguarding element and expansion element of the professional quality, of which the supporting element is the most important and plays a decisive role, with $54 \%$ of the contribution rate, followed by the safeguarding element, the contribution rate of $29.7 \%$, and finally the expansion element, with $16.29 \%$ of the contribution rate.

Viewing from the impact of each factor in the criterion layer $\mathrm{C}$ on the overall objective, $\mathrm{C} 12>\mathrm{C} 23>\mathrm{C} 13>$ $\mathrm{C} 11>\mathrm{C} 31>\mathrm{C} 21>\mathrm{C} 32>\mathrm{C} 22>\mathrm{C} 33$. Through analysis of the communication and coordination, anti-pressure ability, teamwork, hard-working spirit, responsibility, moral integrity, professional skills and other qualities, the enterprises believe that the most important is the professional skills, accounting for $26 \%$ of the weight, followed by moral integrity, accounting for $20 \%$ of the weight. In accordance with the sorting of the importance, other factors are successively the information processing capability, responsibility, anti-pressure ability, moral integrity, teamwork, development potential and communication skills. The detail is shown in Figure 4.

\section{ANALYSIS OF PROFESSIONAL QUALITY OF STUDENTS IN HIGHER VOCATIONAL COLLEGES}

(1) Requirements of employers on the graduates majored with logistics management in higher vocational college

The graduates majored with the logistics management in the higher vocational college are mainly engaged in: the warehouse manager, transport dispatcher, customer service manager, impawning supervision, documentation clerk, customs (inspection) staff, tally clerk, freight forwarding staff, merchandiser, packaging operator, forklift operator and so on. Viewing from the feedback of the surveyed employers, the junior college students can be qualified to the grassroots post of the logistics operations. Some of the positions of the enterprise have formal position de- 

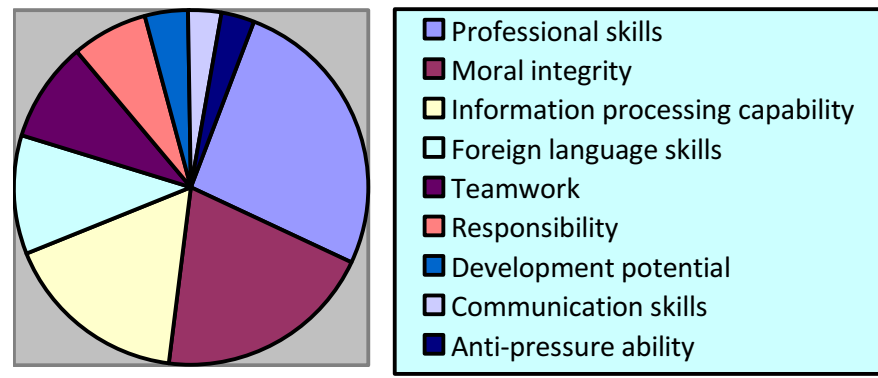

Figure 4. Degree of importance of each factor

scription, and some employers require the students to holding the professional certificate, such as logistics manager (assistant), forklift driving license and so on.

(2) Overall evaluation of the employers on professional quality of students majored with logistics in higher vocational college

Overall evaluation of the employers on the professional quality of students majored with logistics in the higher vocational college: (A) the students graduated from the higher vocational college generally have a relatively strong operational ability, and can be qualified to their own work after entering the employment units. The graduates majored with the logistics management in the higher vocational college are generally the warehouse manager, dispatcher, tally clerk and so on as their initial post after entering the enterprise, and have a relatively large opportunity of promotion within one to three years. (B) Some students have poor communication skills, teamwork ability and anti-pressure ability, and are relatively weak in the customer relation management. As the customer service executives, they have a poor anti-pressure ability in dealing with the customer's after-sales services and complaints and other business. (C) Some students need to improve their employment concepts. Some students have grandiose aims but puny abilities, and are unwilling to engage in the work of grass-roots operation, and believe that they should engage in the management positions as college graduates, so that they have a large gap with their psychological expectations in actual operation positions. (D) With respect to the performance and education background, the enterprises pay more attention to the professional quality of the students graduated from the higher vocational college.

\section{SUGGESTIONS ON TRAINING PROFES- SIONAL QUALITY OF STUDENTS MAJORED WITH LOGISTICS MANAGEMENT IN HIGH- ER VOCATIONAL COLLEGE}

(1) Accurate positioning of training objective of personnel majored with logistics management in higher vocational college

The personnel training relies on the business, connects with the industry, and cooperates with the schools and enterprises, thus jointly establishing the training objective of personnel majored with logistics management. The personnel training highlights the training of the students' professional ability and professional quality, focuses on the development of the students' expansion capacity, and aims at training the personnel with operability of the practical skills and grassroots management personnel.

(2) School-enterprise implementation of "immersion" training, and integration of the professional quality-oriented education into education and teaching

Schools and enterprises have a deep cooperation and commonly build an education platform. The teachers and enterprise personnel commonly establish the personnel training programs, determine the personnel training objective of the professional quality, and analyze the core competence and professional quality possessed by the personnel majored with the logistics management in the higher vocational college. The schools and enterprise commonly construct the curriculum standards and curriculum systems based on the professional quality. Through the introduction of the enterprise projects, work tasks, workflow and other carriers, the students can be devoted to work scenario for learning of knowledge and skills. Various channels and various forms of education can be used for standard management of the students' professional environment, thus developing good professional ethics, professional emotion and professional spirit and promoting the professional identity.

(3) Establishment of the skill and quality evaluation system connected with the enterprise

Schools and enterprises commonly establish a professional quality evaluation system of the logistics. To increase the practices, the traditional evaluation method can be reformed through combination of learning with work and on-duty practice. A real work environment or simulated work scenario can be set up to evaluate the students, thus accurately grasping the students' practical skills and professional quality. In terms of the evaluation content, in addition to the evaluation of the theoretical knowledge and skills, there is also a need to evaluate the students' professional ethics, professional attitude and other aspects.

(4) School-enterprise training of education atmosphere based on the enterprise culture

The formation of the professional quality is a be- 
havior process. The higher vocational colleges integrate the cultural connotation of the logistics industry, enterprise and vocational education into the school education environment, and create the professional scenario by the "cultural symbols", and highlight the professional cultural characteristics ${ }^{[3]}$. Schools and enterprises commonly build a productive training base, and create the work scenario, so that the students can perceive and experience the importance of professional quality in a real work environment, and develop the professional ability and professional personality with simultaneous promotion of the migration and development through practice ${ }^{[4]}$.

\section{ACKNOWLEDGEMENT}

This paper is finally supported by the Task of Hubei Logistics Development Research Centre (15S02).

\section{REFERENCES}

[1] Wu Guanglin. 2009. Theoretical research and practical exploration of professional quality education in higher vocational colleges. China Higher Education Research, (11): 74-75.

[2] Zhang Yougen. 2011. Way to recessive professional quality training of higher vocational students - based on the perspective of "quality iceberg theory". China Adult Education, (20): 5-6.

[3] Tan Manyi, Li Min, Song Gangyong, et al. 2009. New model and its connotation analysis of professional quality. Vocational \& Technical Education Forum, 06.

[4] Ji Fei. 2009. Discussion of effective way of profession quality education in higher vocational college. Education and Vocation, (8).

[5] Li Qiang, Liu Yingming. 2014. Research on reform of personnel training mode of logistics management specialty in higher vocational college based on the enterprise need. Shaanxi Education, (12). 